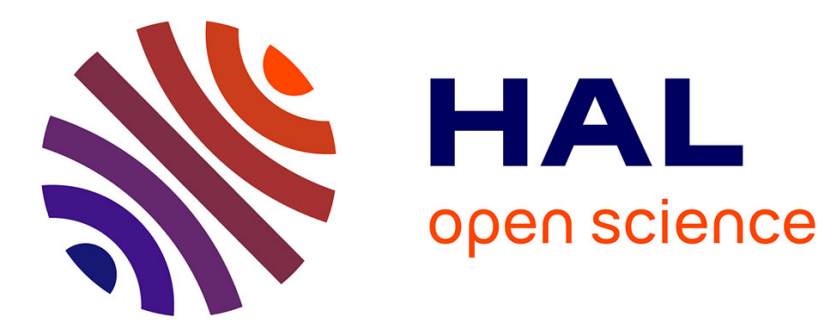

\title{
Real-time crystallization in fluorinated parylene probed by conductivity spectra
}

\author{
Rabih Khazaka, Marie-Laure Locatelli, Sombel Diaham, Christophe \\ Tenailleau, Rakesh Kumar
}

\section{- To cite this version:}

Rabih Khazaka, Marie-Laure Locatelli, Sombel Diaham, Christophe Tenailleau, Rakesh Kumar. Realtime crystallization in fluorinated parylene probed by conductivity spectra. Applied Physics Letters, 2014, vol. 104 ( $\left.n^{\circ} 11\right)$, pp.112902. 10.1063/1.4868646 . hal-01165180

\section{HAL Id: hal-01165180 \\ https://hal.science/hal-01165180}

Submitted on 18 Jun 2015

HAL is a multi-disciplinary open access archive for the deposit and dissemination of scientific research documents, whether they are published or not. The documents may come from teaching and research institutions in France or abroad, or from public or private research centers.
L'archive ouverte pluridisciplinaire HAL, est destinée au dépôt et à la diffusion de documents scientifiques de niveau recherche, publiés ou non, émanant des établissements d'enseignement et de recherche français ou étrangers, des laboratoires publics ou privés. 


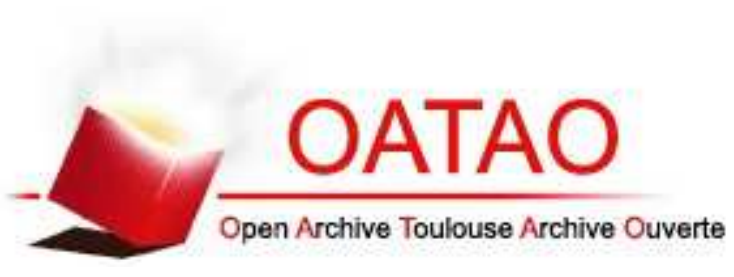

\section{Open Archive TOULOUSE Archive Ouverte (OATAO)}

OATAO is an open access repository that collects the work of Toulouse researchers and makes it freely available over the web where possible.

This is an author-deposited version published in : http://oatao.univ-toulouse.fr/ Eprints ID : 13969

To link to this article : DOI:10.1063/1.4868646

URL : $\underline{\text { http://dx.doi.org/10.1063/1.4868646 }}$

\section{To cite this version :}

Khazaka, Rabih and Locatelli, Marie-Laure and Diaham, Sombel and Tenailleau, Christophe and Kumar, Rakesh Real-time crystallization in fluorinated parylene probed by conductivity spectra. (2014) Applied Physics Letters, vol. 104 ( $\mathrm{n}^{\circ}$ 11). p. 112902. ISSN 0003-6951

Any correspondence concerning this service should be sent to the repository administrator: staff-oatao@ listes-diff.inp-toulouse.fr 


\title{
Real-time crystallization in fluorinated parylene probed by conductivity spectra
}

\author{
R. Khazaka, ${ }^{1, a)}$ M. L. Locatelli, ${ }^{1,2}$ S. Diaham, ${ }^{1}$ C. Tenailleau, ${ }^{3}$ and R. Kumar ${ }^{4}$ \\ ${ }^{1}$ Université de Toulouse, UPS, INPT, Laboratoire LAPLACE, 118 route de Narbonne, F-31062 Toulouse, \\ France \\ ${ }^{2}$ CNRS, LAPLACE, F-31062 Toulouse, France \\ ${ }^{3}$ Université de Toulouse, UPS, Laboratoire CIRIMAT/LCMIE, 118 route de Narbonne - Bât. 2RI, \\ F-31062 Toulouse cedex 9, France \\ ${ }^{4}$ Speciality Coating Systems, Inc. (SCS), Cookson Electronics, 7645 Woodland Drive, Indianapolis, \\ Indiana 46278, USA
}

\begin{abstract}
Dielectric relaxation spectroscopy experiments were performed at high temperature on fluorinated parylene films during the occurrence of the isothermal crystalline phase transition. For this polymer, since the difference between the glass transition temperature $\left(T_{g}\right)$ and the phase transition temperature $\left(T_{c}\right)$ is very strong $\left(T_{c} \geq 4 T_{g}\right)$, segmental and dipolar relaxation usually used to probe the crystallization are not shown in the experiment frequency window $\left(10^{-1}\right.$ to $\left.10^{6} \mathrm{~Hz}\right)$ during the crystallization. The charge diffusion becomes the only electrical marker that allows probing the phase transition. During the transition phase, a continuous decrease of about two orders of magnitude is observed in the conductivity values below an offset frequency $\left(f_{c}\right)$ with a tendency to stabilization after $600 \mathrm{~min}$. Below the offset frequency, the decrease of the normalized conductivity to the initial value as function of time is frequency independent. The same behavior is also observed for the $f_{c}$ values that decrease from $160 \mathrm{~Hz}$ to about $20 \mathrm{~Hz}$. Above the offset frequency, the electronic hopping mechanism is also affected by the phase transition and the power law exponent $(n)$ of the $\mathrm{AC}$ conductivity shows a variation from 0.7 to 0.95 during the first $600 \mathrm{~min}$ that tend to stabilize thereafter. Accordingly, three parameters $\left(n, f_{c}\right.$, and $\mathrm{AC}$ conductivity values for frequencies below $f_{\mathrm{c}}$ ) extracted from the $\mathrm{AC}$ conductivity spectra in different frequency windows seem suitable to probe the crystalline phase transition. (C) 2014 AIP Publishing LLC. [http://dx.doi.org/10.1063/1.4868646]
\end{abstract}

The morphology as well as the crystallization and crystalline phase transition kinetics in polymers have been extensively studied by different techniques such as X-ray scattering, calorimetric and dielectric relaxation spectroscopy (DRS). X-ray scattering techniques do not provide direct information about the dynamic processes occurring within the amorphous phase mainly due to the absence of changes in the order or contrast. However, dielectric spectroscopy techniques have shown to be valuable when dealing with the dynamics of the amorphous chains. Using the latter technique, investigations have been focused mainly on the effect of crystallization on the dipolar relaxation and chain dynamics in the polymer. ${ }^{1-4}$ The amorphous phase segmental dynamics is strongly affected by the progressive development of crystalline phase. The evolution of the dielectric relaxation, associated with the dipolar fluctuations resulting from segmental motions along the chain backbone (known as $\alpha$ relaxation), has been used as a probe for the change in the glass transition dynamics upon crystallization. On the other hand, local motions like the one causing the $\beta$ relaxation are also influenced by crystallinity, and have been shown to be inversely proportional to the amount of crystalline phase. ${ }^{5,6}$ Besides the influence of the crystallization on the molecular dynamics of the polymer chains, it is expected that the increase in the

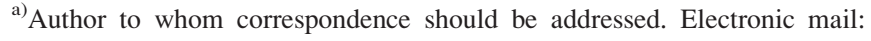
rabih.khazaka@laplace.univ-tlse.fr.
}

crystalline phase lead to a variation in the conductivity and in the polarization effects. Assuming that the conductivity of the crystalline phase is considerably lower than the conductivity of the amorphous one, the conductivity will decrease by the increasing of the crystallization. In addition, the dielectric permittivity at low frequency and/or high temperature, related to the charge motion and/or the boundaries between crystalline and amorphous regions in case of Maxwell-WagnerSillars (MWS) polarization, ${ }^{7}$ will also be affected. As an additional phenomenon leading to the increase in the relative permittivity $\left(\varepsilon^{\prime}\right)$ values observed at low frequency and high temperature, the low frequency dispersion (LFD) described by Jonscher ${ }^{8}$ can also take place, and can also be strongly affected by the charge motions and hence the crystallization.

In the last decades, ionic and electronic conduction phenomena in disordered solids have attracted considerable experimental and theoretical interests. Recently, the study of the charge carrier diffusion in the semi-crystalline structure, during non-isothermal crystallization has been investigated. ${ }^{9}$ However, to the authors' knowledge, the effect of polymers crystalline phase transition and crystallization on the $\mathrm{AC}$ and DC conductivity observed in situ by the DRS technique, has not been reported elsewhere. As aforementioned, most investigations deal with $\alpha$ and/or $\beta$ relaxations that generally appear within the frequency window covered by conventional dielectric spectrometers around the crystallization temperature. 
$\operatorname{Poly}\left(\alpha, \alpha, \alpha^{\prime}, \alpha^{\prime}\right.$-tetrafluoro- $p$-xylylene) fluorinated parylene $\left(-\mathrm{CF}_{2}-\mathrm{C}_{6} \mathrm{H}_{4}-\mathrm{CF}_{2}-\right)$, owning a dielectric constant between 2.25 and $2.9,{ }^{10}$ a high thermal stability above $520^{\circ} \mathrm{C},{ }^{11,12}$ presents the peculiarity to have simultaneously a very high $T_{c}\left(\sim 400^{\circ} \mathrm{C}^{13}\right)$ and a low $T_{g}$ (between $16^{\circ} \mathrm{C}^{14}$ and $100{ }^{\circ} \mathrm{C}^{15,16}$ ). Its good thermal and electrical properties match with the required electrical insulation layers for high temperature electronic devices (exposing materials up to $350^{\circ} \mathrm{C}$ ). However, a crystalline phase transition with an increase in the crystallinity has been observed to occur at temperatures above $300^{\circ} \mathrm{C}$ in such fluorinated parylene films. ${ }^{13,17}$ This can affect, among different properties, the dielectric ones. After having investigated the annealing effect on $\alpha$ and $\beta$ relaxation, ${ }^{17}$ the aim of this paper is to study the effect of the increase in crystallinity during the crystalline phase transition, on the conductivity spectra at high temperature where no frequency dependent contribution from the dipole relaxation is expected in the frequency window since $T_{g} \ll T_{c}$. Hence, the charge carrier diffusion in the semi-crystalline structure during the occurrence of isothermal crystalline phase transition becomes the only electrical marker allowing to probe the phase transition.

Dielectric properties in $\operatorname{Poly}\left(\alpha, \alpha, \alpha^{\prime}, \alpha^{\prime}\right.$-tetrafluoro- $p$ xylylene), named PA-HT were studied using MIMS (MetalInsulator-Metal Structure), where a film of $5 \mu \mathrm{m}$ of thickness was deposited by Polymer Vapor Deposition (PVD) technique on a polished and cleaned stainless steel substrate. Gold circular upper electrodes of $5 \mathrm{~mm}$ in diameter were evaporated in vacuum onto the PA-HT surface in order to achieve the MIMS. Dielectric parameters were characterized at $280^{\circ} \mathrm{C}$ over a wide frequency range $(0.1 \mathrm{~Hz}$ to $1 \mathrm{MHz})$ by dielectric relaxation spectroscopy using a Novocontrol Alpha-A spectrometer with a zero-gradient synchrotron (ZGS) testing cell. The performed dynamic scanning calorimetric (DSC) with a temperature range of $10^{\circ} \mathrm{C} / \mathrm{min}$ on the PA-HT shows that phase transition begin at about $350{ }^{\circ} \mathrm{C} .{ }^{17}$ In our experiments, and in order to allow a long period observation, the temperature choice was fixed about $70^{\circ} \mathrm{C}$ less than the beginning of phase transition occurrence. PA-HT MIMS was placed between two round electrodes and tested. Measurements were made in a nitrogen atmosphere during the whole cycle and the magnitude of $\mathrm{AC}$ applied voltage was $1 \mathrm{~V}$ rms. The heating rate was about $1^{\circ} \mathrm{C} / \mathrm{min}$ until $280^{\circ} \mathrm{C}$. Once the setting temperature was reached, measurements were performed each 5 min during the first period and the interval was enlarged after $30 \mathrm{~min}$. For each measurement, frequency scan from $10^{5} \mathrm{~Hz}$ to $0.1 \mathrm{~Hz}$ was achieved in approximately $5 \mathrm{~min}$. The data were obtained in the form of the dielectric complex permittivity $\varepsilon^{*}=\varepsilon^{\prime}-i \varepsilon^{\prime \prime}$, where $\varepsilon^{\prime}$ and $\varepsilon^{\prime \prime}$ are, respectively, the relative permittivity and the dielectric loss, and $i=\sqrt{-1}$. Before measurements, the sample cell was short and open-circuit corrected and the loss factor accuracy of a $100 \mathrm{pF}$-low capacitor reference was less than $10^{-4}$.

The general $A C$ conductivity features for solids are as follows. At low frequencies and high temperatures, $\sigma^{\prime}(\omega)$ is frequency independent and the value of the plateau region corresponds to the DC conductivity. Around the onset frequency $f_{c}, A C$ conduction sets in. At high frequencies, $\sigma^{\prime}(\omega)$ is close to a frequency power-law with an exponent $n$ between 0.7 and 1.0, which was found to be higher than unity in some cases (and there is no argument to restrict the value of $n$ below than one). ${ }^{18,19}$ The AC conductivity $\sigma_{A C}$ in dielectric materials expressed in the frequency domain may be given by the following universal law: $:^{8,20}$

$$
\sigma_{A C}(\omega)=\omega \varepsilon_{0} \varepsilon^{\prime \prime}(\omega)=\sigma_{D C}+K \omega^{n},
$$

where $\varepsilon_{O}$ is the vacuum permittivity $\left(\varepsilon_{O}=8.854 \times 10^{-12} \mathrm{~F} \mathrm{~m}^{-1}\right)$ and $\sigma_{D C}$ corresponds to the low frequency value when $\sigma_{A C}$ becomes frequency independent (plateau region), $K$ is a temperature dependent parameter and $n$ is the exponent of the power law. Actually, during the AC electric polarization of a material, the charge carriers scan a distance corresponding to the period of the electrical field. Hence, at low frequencies, the carrier charges have enough time to scan different amorphous regions leading to a normal diffusion and the DC conductivity is determined by overcoming of unfavorable places in the solid for the formation of a continuous "percolation" path between the electrodes. At higher frequencies, the carriers are expected to travel only within small amorphous areas and better use is made of the "conductive" places with very large jump probability. Thus, the conductivity approaches the DC value at low frequencies and increases with frequency.

However, the AC conductivity spectra at various dwell times at $280^{\circ} \mathrm{C}$ of the parylene $\mathrm{HT}$ are not corresponding exactly to the aforementioned features as it can be seen in Fig. 1. At low frequencies, conductivity is slightly frequency dependent without the presence of a clear plateau. Accordingly, the true DC conductivity values cannot be extracted from Fig. 1 due to another behavior known as LFD. This phenomenon is distinguished from pure DC conduction by an increase in the charge storage $\left(\varepsilon^{\prime}\right)$ (not shown here). The LFD behavior represents an extension of the aforementioned universal law, with a different power-law index. $^{21}$ The LFD mechanism is not fully understood yet and has been the subject of different studies. In Ref. 22, the LFD has been related by Dissado et al. to the large occupancy factor which allows the bound species to interact one with another, so as to modify the regularity of the inter-site spacing in the material bulk. In Refs. 23 and 24, Jonscher has suggested a model for the LFD in which the storage of

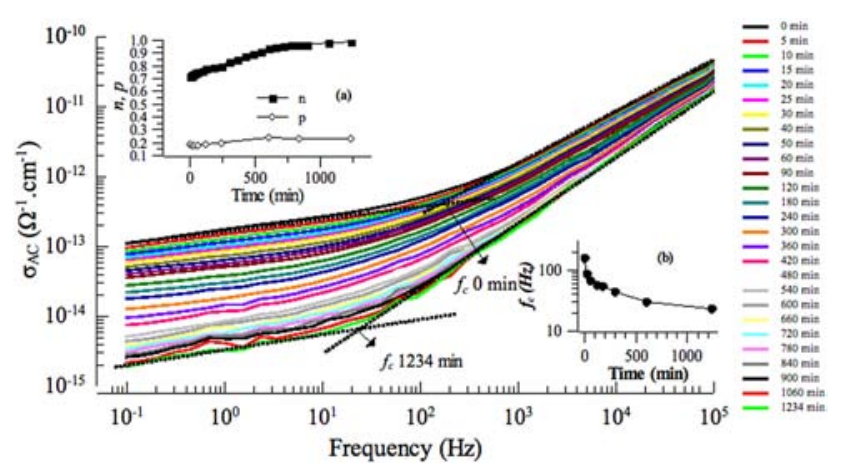

FIG. 1. Decrease of AC conductivity values vs time during the transition phase crystallization occurrence at $280{ }^{\circ} \mathrm{C}$. The inset graph (a) presents, respectively, the variation of $n$ and $p$ exponents. The inset graph (b) presents $f_{c}$ against time. The values of $n, f_{c}$, and AC conductivity show noticeable variation during the first $600 \mathrm{~min}$ at $280^{\circ} \mathrm{C}$ followed by quasi-stabilization. 
charge and of energy takes place electrochemically and not electrostatically. Recently, the effect of electrochemical storage between the charged metallic electrodes and the tested material ions on the increase in $\varepsilon^{\prime}$ and the decrease in $\sigma^{\prime}$ has been evidenced. ${ }^{25,26}$

The $n$ and $p$ exponents are defined by $\mathrm{d} \log \left(\sigma^{\prime}\right) / \mathrm{d} \log (\omega)$ above and below $f_{c}$, respectively. Their values are obtained from the slope of straight lines in graph $\log \left(\sigma^{\prime}\right)$ versus $\log (\omega)$ and are represented in the inset (a) of Fig. 1. The $n$ parameter has been used to understand the electronic hopping process in polymer material. ${ }^{27,28}$ The power law dependence of conductivity has been related to the intrinsic disorder of the amorphous phase. ${ }^{9}$ In our study, $n$ shows continuous increase and tends toward a constant value of 1 during the isothermal storage at $280^{\circ} \mathrm{C}$. Accordingly, and since the electronic hopping process is influenced by the transition phase occurrence, it seems reasonable to conclude that the polymer amorphous phase morphology varies during the transition phase occurrence. On the other hand, the $p$ parameter seems independent on the dwell time at $280^{\circ} \mathrm{C}$. This can highlight that the variation of the crystalline regions properties during the transition phase occurrence (crystallites size and number as well as the inter-reticular distance) did not affect the LFD mechanism. The inset (b) of Fig. 1 represents the variation of the extracted $f_{c}$ against time. According to Dyre theory, the $f_{c}$ value corresponds to the maximal frequency needed for the charge carriers to overcome the highest energy barrier limiting the dc conductivity. ${ }^{18}$ The $f_{c}$ value tends to decrease steeply during the first $60 \mathrm{~min}$ followed by a slower decrease. This indicates the increase of the highest energy barrier during the crystallization occurrence and than longer time required by charge carriers to overcome it.

The decrease in the $\sigma_{A C}$ values normalized to the initial measured one for different frequencies during the storage at $280^{\circ} \mathrm{C}$ is presented in Fig. 2. At frequencies below $10 \mathrm{~Hz}$ the variation seems to be frequency independent and is related to the variation of the mesoscopic conduction phenomenon. The decrease of about two orders of magnitude can be explained

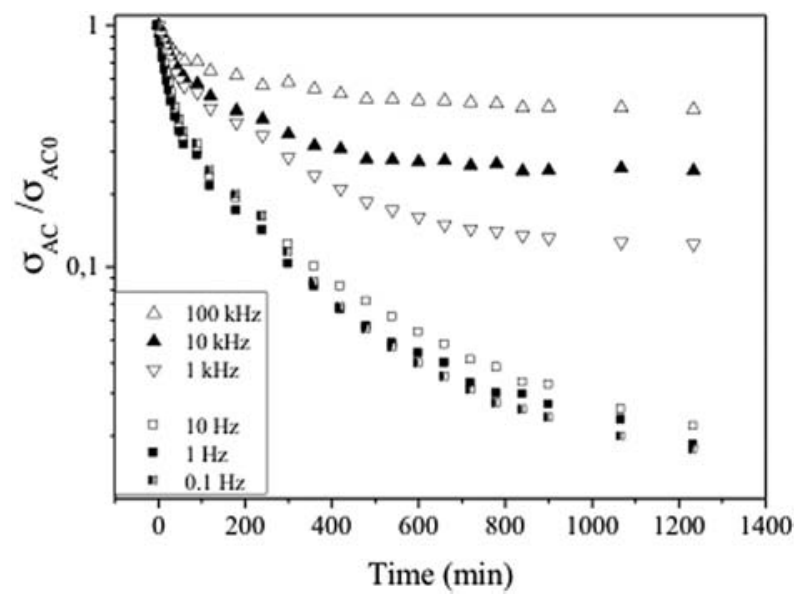

FIG. 2. Variation of $\sigma_{A C}$ normalized to the initially measured value $\sigma_{A C O}$ during the dwell time at $280^{\circ} \mathrm{C}$ for different frequencies. Data for frequency values between $10 \mathrm{~Hz}$ and $1 \mathrm{kHz}$ are not presented since the conduction mechanism varies with the time. For frequencies below $10 \mathrm{~Hz}$, the variation of normalized $\sigma_{A C}$ values are identical. For frequencies above $1 \mathrm{kHz}$, the variations of normalized $\sigma \mathrm{AC}$ values as well as the stabilization time are frequency dependent. by the decrease in the mobile charge density, the increase of the energy barrier already mentioned and the increase of the percolation paths length induced by the reduction of the conductive amorphous phase transferred to the crystalline phase. In addition to those simplified and evident reasons, amorphous phase variation suggested during the investigation of the electronic hopping process may have a significant role. In fact, we assume that the growing crystals or additional secondary ones may act as physical cross-links in the amorphous phase slowing down the charge dynamic inside. Hence, the increase in crystallization not only reduces the charge density due to their incorporation within crystallites, but also may constrain additional amorphous material located adjacently to the crystals, and known as rigid amorphous phase (RAP). This RAP has been evidenced by several authors, and affects closely the chain relaxation mechanisms. ${ }^{4,29,30}$ It is believed that the effect of RAP can be extended to conductivity values since the conductivity in polymers has long been viewed as confined to the amorphous phase above the glass transition temperature, where polymer chains motion creates a dynamic disordered environment facilitating the charge transport. ${ }^{31} \mathrm{By}$ increasing frequencies (above $1 \mathrm{kHz}$ in our case), the stabilization times of the AC conductivity decrease during the storage and the variation of normalized AC conductivity values also decreases. In fact, at the highest test frequencies, the scanned most conductive regions in amorphous phases are slightly affected by the phase transition occurrence. On the contrary, by decreasing the frequency, phases with lower conductivities are scanned as well, and the latter are more affected by the phase transition and longer periods are mandatory to reach constant values.

Since this crystalline transition phase can improve the low field dielectric properties, the optimal storage time needed at a defined temperature to accomplish the crystalline phase transition is very useful and can be monitored by three parameters obtained from the AC spectra in different frequency windows: the below $f_{\mathrm{c}}$ conductivity values, the $f_{\mathrm{c}}$ values and the power law exponent $n$ values.

In order to observe changes in the film crystallinity, wide angle X-ray diffraction (WAXD) was performed before and after the dielectric measurement at $25^{\circ} \mathrm{C}$ with a $\mathrm{CuK} \alpha$ radiation $\left(\lambda=0.15418 \AA\right.$ 自) using a $1^{\circ}$ grazing incidence angle over $10^{\circ}$ to $80^{\circ}$ in $2 \theta$ with a $0.02^{\circ}$ step size and $10 \mathrm{~s} / \mathrm{step}$ scans. The observed peak is related to the 100 planes lying parallel to the film surface that are well detected by our experimental technique. According to Fig. 3, the peak intensity increases and it shifts towards higher angles $2 \theta$. This reveals that the overall crystallinity of the parylene films increases after the isothermal storage. The crystallite size varies from $4.7 \mathrm{~nm}$ up to $5.9 \mathrm{~nm}$ and the inter-reticular distance decreases from $4.64 \AA$ to $4.42 \AA$ after the $1240 \mathrm{~min}$ of storage at $280^{\circ} \mathrm{C}$. Generally, the evolution of crystallinity with time is defined by Avrami equation and shows sigmoidal shape. ${ }^{30,32}$ Due to the initial role of RAP in the conduction mechanism as well as the possible beginning of the crystalline phase transition before the first measurement at $280^{\circ} \mathrm{C}$, it was expected that the evolution of dielectric did not fit the Avrami equation. Otherwise, it has been found that the transition phase temperature obtained by dynamic scanning calorimetry experiments of fluorinated films was higher than the 


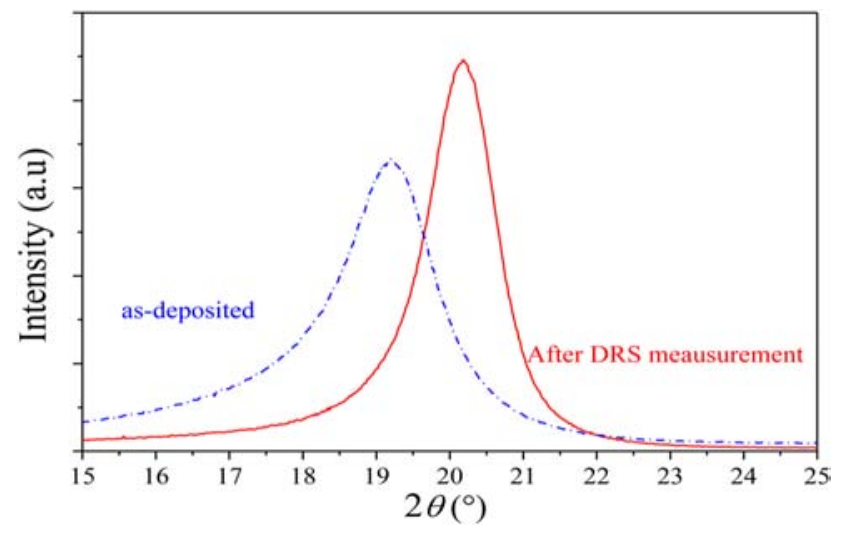

FIG. 3. Variation of the WAXD spectra before and after isothermal DRS measurement at $280^{\circ} \mathrm{C}$. An increase on crystallinity after the DRS measurement can be observed from the higher intensity of peak and its shift toward higher angles.

temperature extracted from dielectric spectroscopy. ${ }^{17}$ This difference is most probably due to the confinement of the film by the substrate inducing the compressive thermal stress in the plane of the substrate-confined films and causing the conversion to the higher temperature phase at lower transition temperature than observed for the free standing films studied by the DSC. ${ }^{13}$

In summary, conductivity spectra in PA-HT films using MIMS were investigated by DRS at high temperature during the isothermal crystalline phase transition occurrence. This represents a great theoretical and experimental interest to understand the relation between the film crystallinity and different parameters extracted from conductivity spectra, and to improve the high temperature low field dielectric properties by an optimized annealing time. During the first period of dwell time, the values of the conductivity for frequencies lower than $f_{c}$ are strongly affected by the crystalline phase transition and the increase of crystallinity, and values tend to stabilize. The power exponent $n$ and the offset frequency $f_{c}$ show values with a strong variation during the first $600 \mathrm{~min}$ and a tendency to stabilize with time. This observation leads us to conclude that $n, f_{c}$, and $\sigma_{A C}$ for $f<f_{\mathrm{c}}$ can be used as a probe of the transition phase of PA-HT. The high frequency hopping process shows a variation during the crystallization occurrence and the variations of normalized values as well as the stabilisation time are frequency dependent. The increase of crystallinity is observed by WAXD before and after the measurement. However, we are aware that for a more complete scheme and a better understanding of the conductivity spectra of semi-crystalline polymers during the crystalline transition phase, a completed analysis of the crystalline structure evolution should be obtained by the real time evolution of the XRD spectra.

${ }^{1}$ T. A. Ezquerra, F. J. Baltà-Calleja, and H. G. Zachmann, Polymer 35, 2600 (1994).

${ }^{2}$ T. A. Ezquerra, J. Majszczyk, F. J. Baltà-Calleja, E. Lopez-Cabarcos, K. H. Gardner, and B. S. Hsiao, Phys. Rev. B 50, 6023 (1994).

${ }^{3}$ T. A. Ezquerra, Z. Roslaniec, E. Lopez-Cabarcos, and F. J. Baltà-Calleja, Macromolecules 28, 4516 (1995).

${ }^{4}$ A. Nogales, T. A. Ezquerra, Z. Denchev, I. Šics, F. J. Baltà-Calleja, and B. S. Hsiao, J. Chem. Phys. 115, 3804 (2001).

${ }^{5}$ M. Soccio, A. Nogales, N. Lotti, A. Munari, and T. A. Ezquerra, Phys. Rev. Lett. 98, 037801 (2007).

${ }^{6}$ M. Soccio, A. Nogales, N. Lotti, A. Munari, and T. A. Ezquerra, Polymer 48, 4742 (2007).

${ }^{7}$ F. Kremer and A. Schönhals, Broadband Dielectric Spectroscopy (Springer-Verlag, Berlin/Heidelberg, 2003).

${ }^{8}$ A. K. Jonscher, Dielectric Relaxation in Solids (Chelsea Dielectrics Press, London, 1983).

${ }^{9}$ I. Alig, S. M. Dudkin, W. Jenninger, and M. Marzantowicz, Polymer 47, 1722 (2006).

${ }^{10}$ B. Hanyaloglu, A. Aydinli, M. Oye, and E. S. Aydi, Appl. Phys. Lett. 74, 606 (1999).

${ }^{11}$ K. R. Williams, J. Therm. Anal. 49, 589 (1997).

${ }^{12}$ B. L. Joesten, J. Appl. Polym. Sci. 18, 439 (1974).

${ }^{13}$ M. Morgen, S. H. Rhee, J. H. Zhao, I. Malik, T. Ryan, H. M. Ho, M. A. Plano, and P. Ho, Macromolecules 32, 7555 (1999).

${ }^{14}$ A. S. Harrus, M. A. Plano, D. Kumar, and J. Kelly, Mater. Res. Soc. Symp. Proc. 443, 21 (1997).

${ }^{15}$ S. W. Chow, W. E. Loeb, and C. E. White, J. Appl. Polym. Sci. 13, 2325 (1969).

${ }^{16}$ S. Y. Park, J. Blackwell, S. N. Chvalun, K. A. Mailyan, and I. E. Kardash, Macromolecules 32, 7845 (1999).

${ }^{17}$ S. Diaham, M. Bechara, M.-L. Locatelli, and T. Lebey, J. Appl. Phys. 110, 063703 (2011).

${ }^{18}$ J. C. Dyre and T. B. Schrøder, Rev. Mod. Phys. 72, 873 (2000).

${ }^{19}$ A. N. Papathanassiou, I. Sakellis, and J. Grammatikakis, Appl. Phys. Lett. 91, 122911 (2007)

${ }^{20}$ A. K. Jonscher, Nature 267, 673 (1977).

${ }^{21}$ A. Jonscher, J. Phys. D: Appl. Phys. 32, 57 (1999).

${ }^{22}$ L. Dissado and R. Hill, J. Chem. Soc., Faraday Trans. 2 80, 291 (1984).

${ }^{23}$ A. Jonscher, Electr. Insul. Mag. 6(4), 19 (1990).

${ }^{24}$ A. Jonscher and T. Ramdeen, IEEE Trans. Dielectr. Insul. E1-22(1), 35 (1987).

${ }^{25}$ A. Serghei, M. Tress, J. R. Sangoro, and F. Kremer, Phys. Rev. B 80, 184301 (2009).

${ }^{26}$ J. R. Sangoro, A. Serghei, S. Naumov, P. Galvosas, J. Kärger, C. Wespe, F. Bordusa, and F. Kremer, Phys. Rev. E 77, 051202 (2008).

${ }^{27}$ S. Chisca, V. E. Musteata, I. Sava, and M. Brum, Eur. Polym. J. 47, 1186 (2011).

${ }^{28}$ R. Khazaka, M. L. Locatelli, S. Diaham, P. Bidan, L. Dupuy, and G. Grosset, J. Phys. D: Appl. Phys. 46, 065501 (2013).

${ }^{29}$ I. Šics, T. A. Ezquerra, A. Nogales, Z. Denchev, C. Alvarez, and S. S. Funari, Polymer 44, 1045 (2003).

${ }^{30}$ A. Sanz, A. Nogales, T. A. Ezquerra, M. Soccio, A. Munari, and N. Lotti, Macromolecules 43, 671 (2010).

${ }^{31}$ Z. Gadjourova, Y. G. Andreev, D. P. Tunstall, and P. G. Bruce, Nature 412, 520-523 (2001).

${ }^{32}$ A. K. R. Dantuluri, A. Amin, V. Puri, and A. K. Bansal, Mol. Pharmaceutics 8, 814 (2011). 